\title{
Science Education Needs a Multilevel Approach
}

\author{
Matthias von Arx* and Peter Labudde
}

\begin{abstract}
Triggered by an increasing consensus on the importance of science education for the economy and society as a whole, in recent years, a growing number of educational programs, initiatives and projects have been launched by various players (from educational policy makers over teacher education institutions to industry). Many of these initiatives have a direct or indirect link to molecular sciences. In this article, we develop a twodimensional framework which can be used as a guideline in the classification and discussion of existing projects as well as in the planning and design of future initiatives. The framework incorporates three organizational levels or groups of persons and the two very central fields of objectives 'knowledge and skills' and 'motivation and interest'. On the basis of this framework, we discuss four projects in which our science and technology education center has been involved, with respect to their influence on the knowledge, skills and interest of pupils, teachers and school administration representatives in science.
\end{abstract}

Keywords: Motivation · Pupils · Science education · Skills · Teachers

\section{Molecular Sciences in School?}

In school, a subject 'molecular sciences' does not exist, at least not before the secondary two level. In many Swiss cantons, not even chemistry, biology or physics exist as subjects in the curriculum, because science ${ }^{[1]}$ is taught in an integrated approach (in subjects called e.g. 'Natur Mensch-Gesellschaft' (Nature-Mankind - Society) or 'Natur und Technik' (Nature and Technology).[2,3] So what can school as an institution, teachers, teacher educators or policy makers and industry do to foster both interest and basic knowledge in molecular sciences? Actually a lot![4] However, one has to distinguish between different purposes and different levels.

It is not the responsibility of compulsory school (grades 1-9) to prepare pupils for university, but for apprenticeship and professional life, or more generally, for life as an active member of society. ${ }^{[5,6]}$ Upper secondary school (gymnasium) on the other hand has to ensure both admission to university in a broad range of subjects and a solid body of knowledge in various

\footnotetext{
${ }^{*}$ Correspondence: Dr. M. von Arx

Zentrum Naturwissenschafts- und Technikdidaktik Pädagogische Hochschule FHNW

Riehenstrasse 154

$\mathrm{CH}-4058$ Basel

Tel.: +41616901956

Fax: +41614674969

E-mail: matthias.vonarx@fhnw.ch
}

fields (notably in natural sciences!) for future decision makers. Considering the lack of experts in the fields of technology, natural sciences and life sciences, not only on university grade level, but also on the level of qualified technical personnel, this is a task of paramount importance which is not easily achieved, given the small number of lessons reserved for the natural science subjects in the curriculum and the rather common prejudice of a high number of people that these subjects are difficult, abstract, boring or even superfluous.

In section 2 we propose a simple twodimensional framework which can be used as a guideline in the development of programs for pupils, teachers or schools as a whole. It describes how to set something in motion, on which level and with which objective. The same framework can also be used to discriminate between different approaches pursued in various existing programs or projects. In section 3 we present a selection of projects developed at our science and technology education center in the last two years, and they are discussed with reference to the framework described in section 2 .

\section{A Two-dimensional Framework}

In recent years there has been an increasing awareness of the importance of basic science knowledge for society as a whole. The start of this trend can probably be traced back to the AAAS Initiative in the US, which has led to the definition of the 'nature of science' concept, ${ }^{[7]}$ and has influenced the development of science standards in many countries ${ }^{[8]}$ as well as the concept of 'scientific literacy' in PISA (Program for International Student Assessment). ${ }^{[9,10]}$ In the meantime, a variety of developmental programs and initiatives have been implemented on various institutional levels and even the industry has started to invest money for such programs, some of which are presented in this CHIMIA special issue.

How can all these programs and initiatives be classified? How can one keep an overview? What is the value of such programs? Or to put it simple: what is a good program? There is no easy and straightforward answer to this question, and any answer will depend on the perspective taken. Nevertheless, we propose a simple, two-dimensional framework which can be used as a guideline for our discussion.

The framework (Fig. 1) is spanned by a first dimension including the three levels or groups of people 'pupil', 'teacher' and 'school administration' (y-axis) and a dimension field of objectives including 'knowledge and skills' and 'motivation

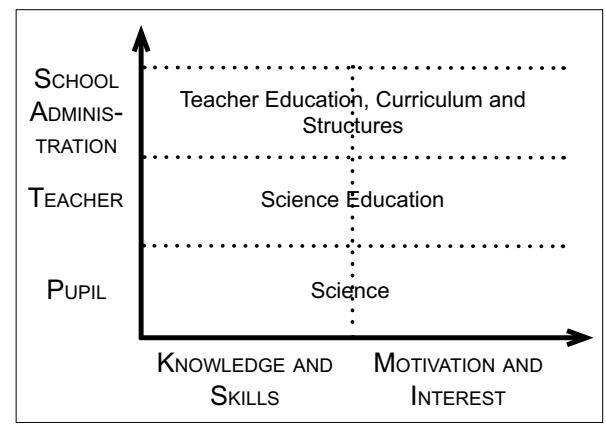

Fig. 1. Two-dimensional framework for the classification of existing and future programs/ initiatives for schools. 
and interest' ${ }^{[11,12]}(x$-axis). This leads to a $2 \times 3$ matrix with 6 elements which can be used as a basis for classification and discussion. We neither claim this framework to be complete nor to be empirically validated. Still, we consider it to be valuable for the purposes of classifying initiatives in order to develop and improve science education.

The field of objectives dimension features a cognitive part, 'knowledge and skills', and an affective part, 'motivation and interest'. Both parts play an important role in science education ${ }^{[13]}$ on all levels. 'Knowledge' includes a broad spectrum of different types of knowledge, amongst others:

- factual knowledge, e.g. knowing the symbols of chemical elements or the definition of the $\mathrm{pH}$-value,

- so-called procedural knowledge, e.g. knowing how to set up and to calculate stoichiometric equations,

- knowledge about the nature of science, e.g. the understanding of the interplay between theory and experiments or the knowledge of the role, advantages and limits of models.

'Skills' play a major role in science education on all levels, from pre-school to university. In many frameworks and curricula, they are noted in so-called 'cando descriptions'. For example the Swiss framework 'Basic competences for science', [14] states: "[At the end of $9^{\text {th }}$ grade,] pupils can:

- conduct specific measurements, gather, arrange and compare data in order to describe phenomena;

- distinguish descriptions and assessments of facts/issues and give reasons for them from different perspectives/point of views as well as to formulate, describe and reflect on different evaluations in statements.

- contribute to the planning of a project in science by developing subtasks and applying them on their own or in collaboration with others."

Knowledge and skills are the core and the main objectives of science instruction all over the world. However, they are always framed by affective goals. Pupils should be motivated by scientific questions, phenomena, processes and devices. They should develop interest ${ }^{[11]}$ in chemistry, physics, and biology - in the best case, they develop a life-long interest and curiosity. The Swiss framework mentioned above, states: "[Pupils are expected to] develop the joy and willingness necessary for the examination of questions concerning science, technology, health and sustainable development and establish lasting interests."

The y-axis represents the different levels or groups of people that are involved in education. First of all, the pupils are the final focus of any educational endeavor. Even more, young people can be seen as seed crystals of any future development. Therefore, many programs in science education focus on the pupil; e.g. experts develop new teaching materials, prepare new science content in a way to make it accessible for pupils of various grades (e.g. nanotechnology, mission to the Mars).

Other programs focus on teachers or - vice versa - teachers initiate and run a program. This is why the second level is dedicated to teachers. It includes two aspects: First, teachers learn new science and science education content, i.e. new knowledge and skills, and learn to apply them in the classroom. Second, they - in particular primary school teachers - are motivated and interested in teaching science. One has to keep in mind that teachers are the key players in all educational systems. No program will have a sustained effect, if it does not have an influence on everyday teaching performed by regular teachers in their classes.

The third level deals with the school management and administration, i.e. it covers the range from head of a school and school management to ministry of education and policy makers. All of them are responsible for the context of science education, either within a school or within the educational system. On this level, the basic conditions for science education are set, including e.g. curricula, lesson tables, teacher education schemes and special developmental programs.

\section{Examples}

Not all of the examples described below have an obvious link to or focus on molecular sciences. However, programs for the advancement of children's, teenagers' or teachers' knowledge about, and interest in natural sciences build a basis for any more specific contact with molecular sciences at a later stage. Furthermore, there are many possibilities to include references to molecular sciences in more general programs designed for grades 1-9.

\section{1 iLab}

The iLab ('Das Labor für die iPod Generation', the lab for the iPod generation) is situated at the Paul Scherrer Institute (PSI) near Villingen. It has been conceptualized and implemented by a team of researchers from PSI, under the lead of Dr. Fritz Gassmann. The aim of the lab is to give children and teenagers an opportunity "to perform interesting experiments in a learning by doing manner" and, in this way, to "get insight into contents and methods characteristic of research. The teenag- ers can figure out, without any pressure to succeed, whether the way physicists approach things is fun or not."[15]

The things they approach are the vacuum and sound waves. In other words, there is a series of experiments for each of these two topics. In a pedagogically clever way, the phenomena (e.g. reflection, dispersion and superposition of waves) are linked first with everyday knowledge or questions of the kids (e.g. "how can a bat avoid flying into a wall?" Or, "how can a bat distinguish between another bat or a mosquito, in other words: food?"). Then, by analogy, a link to a research question such as, "how can the size and shape of a molecule or atom be determined?", is possible. You just need a different type of waves with smaller wavelengths and different detectors. Through a mixture of trying to find out by themselves and being coached by the iLab-staff, pupils can get insight into a very basic and fundamental principle of molecular sciences, namely spectroscopy.

From this short description it becomes clear that the focus of the iLab is on the pupils. The setting allows children and teenagers to build some new knowledge on their existing knowledge, to advance their skills in "how to find out something by experimentation" and to trigger interest in such topics and methods. This is schematically illustrated by the dark grey shading of the two corresponding elements in Fig. 2a.

The whole setting is a true story of success. Since the opening of the lab in 2008, approximately 10 '000 pupils have visited the lab. The pattern in Fig. $2 a$ is quite a

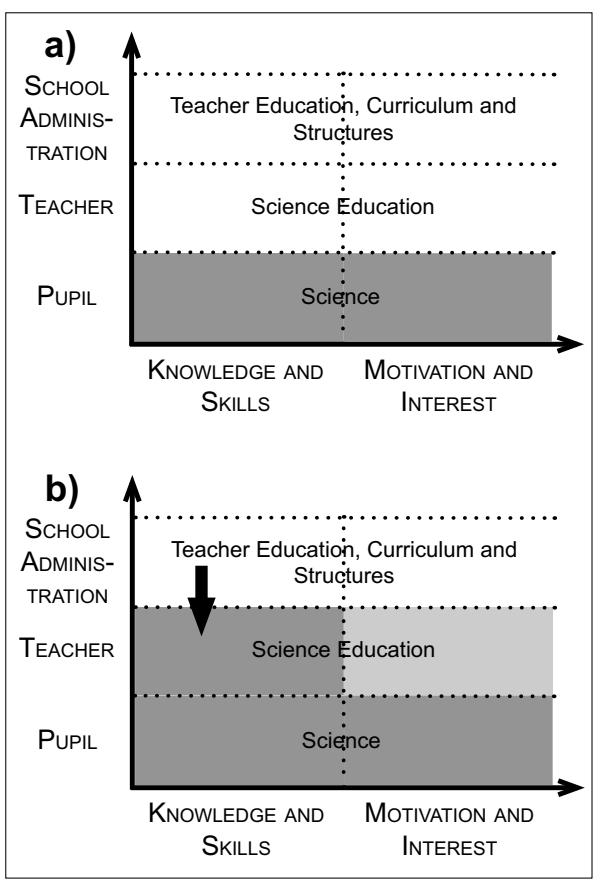

Fig. 2. Schematic classification of the iLab according to the two-dimensional framework, a) in its original version and b) after the complementation with a teacher brochure. 
common pattern. Many of the programs we know and some of those described in this CHIMIA special issue follow/share a very similar pattern. However, one can argue that from the perspective of a pupil, the visit of the iLab typically remains a nice, but rather isolated event, only poorly linked with science instruction at school. Unfortunately, this is a rather common fact. To improve the embedding of the visit of the iLab in a sequence of instruction at school, the school administration of the canton Aargau (Departement Bildung, Kultur und Sport, BKS des Kanton Aargau) together with the PSI initiated the development of a brochure for teachers. The aims of the brochure are:

- To provide teachers with background information on the topics covered by the iLab (content knowledge).

- To provide teachers with information on how to link the experience of the iLab with the curriculum (educational knowledge).

- To give examples of experiments that can be performed at school and help consolidate the theory learned at the iLab. In this way, the positive experience of "how you can find out something by experimentation" is carried into school and therefore renewed and strengthened (educational knowledge and skills).

- To provide teachers with specific ideas on how to embed the visit in a sequence of regular lessons to have a more sustained effect, both on the cognitive and affective sides (educational skills).

Considering this supplement, the classification according to our two-dimensional framework of the iLab can be changed as illustrated in Fig. 2b. The inclusion of the element of educational knowledge and skills of the teacher, as initiated by the school administration level (indicated by the arrow) and to a lesser extent the motivation and interest of the teacher (indicated by the light grey shading because there is less emphasis on this aspect), allow for a longer lasting and therefore more sustained effect of the experience.

\subsection{Strawberries in Winter - A Climate Fairy Tale}

Another way to bring pupils in contact with a topic of high scientific and social impact is an exhibition. Quite often, museums plan special exhibitions specifically designed for young people. For example, in the last couple of years there have been several initiatives in the context of climate change, the most recent being the exhibition 'Strawberries in Winter - A Climate Fairytale' (Erdbeeren im Winter - ein Klimamärchen), which started in Bern in March 2012 and will tour through Switzerland until 2015.

In order to understand the mechanisms leading to an increase in atmospheric $\mathrm{CO}_{2}$ and consequently to climate change, pupils need some very basic knowledge in chemistry and physics. Where does the $\mathrm{CO}_{2}$ come from? How is it produced? What happens, when radiation interacts with matter (e.g. $\left.\mathrm{CO}_{2}\right)$ ? How is it possible that some 'types' of radiation can pass through the atmosphere while other 'types' cannot? The discussion of these questions allows the introduction of some very basic concepts, not typically included in curricula. What would molecular sciences be without our knowledge on the interaction of radiation with matter?

However, the main focus of a special exhibition typically is not to teach basic concepts. An exhibition has to offer much more, e.g. by the use of audio, visual and multimedia material, which is orchestrated in a way to pursue a specific goal. In the case of 'Strawberries in Winter' this purpose is to 'sensibilize' (young) people and to show 'options to act for consumers ... and as citizens' ${ }^{[16]}$ For this reason, the focus of the exhibition, its objects and its productions are clearly on the affective side (as illustrated in Fig. 3a). After the visit, the visitor should feel both an urge to act and the confidence that everyone has opportunities to act. Still, there is a need for some basic knowledge, and that is where our science and technology education center comes into play.

Already very early in the conception and planning of the exhibition, it was clear that the exhibition should be complemented by material specifically designed for schools.

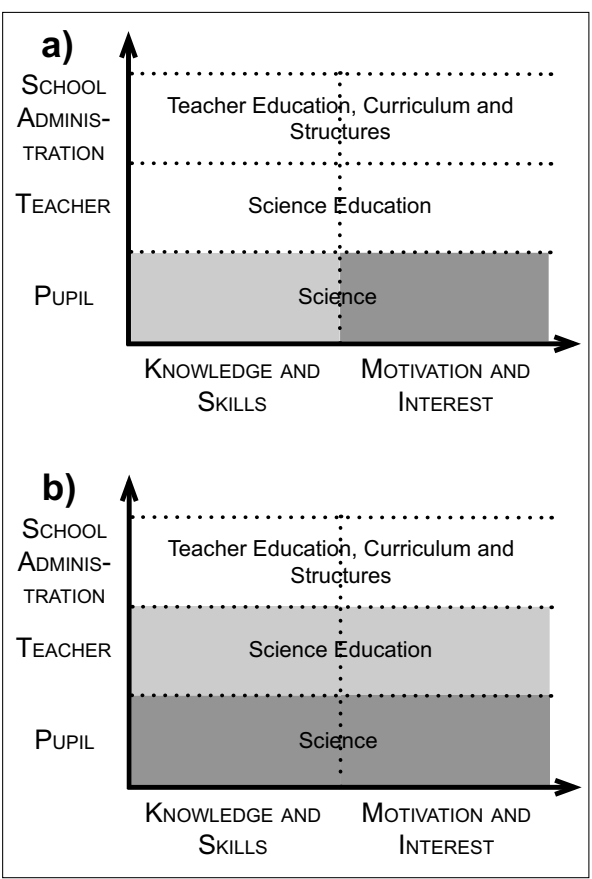

Fig. 3. Schematic classification of the exhibition 'Strawberries in Winter - A Climate Fairytale' according to the two-dimensional framework, a) the exhibition alone b) together with the additional material provided for schools.
The exhibition should fascinate, excite and motivate visitors, while teachers, before the visit at the exhibition, should provide the pupils with exactly those bits of information and knowledge they need in order to understand the exhibition with the aid of the additional material. Ideally, teachers could also profit from the (probably excited) affective state of the pupils after the visit, use it as starting point for further discussions or even the development of an own school or class action program, aiming e.g. at the reduction of $\mathrm{CO}_{2}$ emissions. For this reason, the additional material provides the teachers with a wealth of information, links and ideas for class action programs and how to set them up.

In this sense, the exhibition and the accompanying material are truly complementary, both profiting from each other and in this way enhancing the effect of the visit at the exhibition (illustrated in Fig. $3 b)$.

\subsection{Hi-Tec!}

The next project has been initiated by our own School for Teacher Education FHNW together with the School of Architecture, Civil Engineering and Geomatics FHNW, the School of Engineering FHNW and with financial support by a partner from the industry. The aim is to bring topics of high relevance from the field of technology into science classrooms by combining expertise from scientists with the educational expertise of our science and technology education center. The four topics covered so far are GPStracking, carbon fiber reinforced plastic (CFRP), thermal insulation and robotics. Although CFRP and thermal insulation have clear links to molecular sciences, there is no subproject yet with an exclusive focus on a molecular science topic. Once the funding is secured, an extension of the project into this area is planned.

The main objective of this program is motivation and interest on all levels (see Fig. 4). It is the motivation of the project leaders to close this gap in textbooks and to get pupils and teachers in contact with topics of high topicality and social relevance. Topics or objects the pupils know from their surroundings, and which have an influence (consciously or subconsciously) on their lives. Many pupils are keen to know how those things work and what lies behind their functioning because they realize it as being relevant. Teachers are interested in examples of how to tackle such things in the classroom, without having to be a CFRB expert themselves. Of course, there is also the knowledge and skills side of the project. The four topics should not just be fun, but the pupils should also learn something interesting. However, the level has to be appropriate and focus on very 
basic concepts, which can open doors for later. For example:

- The pupils can gain some fundamental insight into the structure-properties relationship of matter by using analogies and pictures and without any complicated chemical formulae or detailed discussion of polymerization (CFRP project).

- The pupils can gain fundamental insight into the problems of communication between man and machine and learn the concept of 'program sequence' or 'loop' without having to dig deep into the painstaking realms of programming (robotics project).

For the secondary one level (grades 7-9) this is the appropriate way of helping to develop the motivation and endurance needed for a more detailed tackling of the problems on secondary two or tertiary level.

\subsection{SWISE}

The program or initiative serving as the final example is by far the largest and in its conception quite different from the programs presented so far. SWiSE, standing for Swiss Science Education, is a school and education development program for kindergarten through to grade 9 and its teachers in the German-speaking part of Switzerland, with a clear focus on science education. It is a joint project of six schools for teacher training (Pädagogische Hochschulen) and additional teacher training institutions and is funded with 3 million Swiss Francs by three foundations (Mercator, Avina, Ernst Göhner) and fourteen cantonal ministries of education.

It is not our aim to give a full description of the project here. Instead, we will focus on the sub-project 'SWiSE Schools' ('SWiSE Schulen'). For a full overview see the web-page. ${ }^{[17]}$ The main objectives of the project 'SWiSE-Schools' are:

- to support teachers - independent of their science background - in the advancement of their science instruction and their openness towards and interest in science education,

- to accompany teachers in the installa-

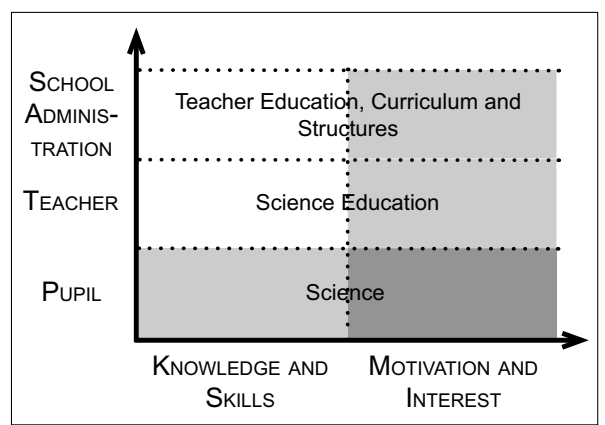

Fig. 4. Schematic classification of the initiative 'Hi-Tec!', according to the two-dimensional framework. tion of networks of science teachers within school and between schools in order to profit from an exchange of knowledge, know-how and resources,

- to qualify teachers for inquiry-based learning approaches to teaching at all school types and school grades,

- to promote teachers in the implementation of more skill and competence oriented ways of teaching.

In other words: From a strategic point of view, the program's most central focus lies on the teachers, who, in the long run, have always been and always will be the key element in any educational development. In the field of science education, this is of special importance because most kindergarten and primary school teachers (grades 1-6) and many secondary I level teachers (grades 7-9) have had no or only sparse training in science education. For this reason, the implementation of the four points mentioned above is promoted by a series of additional measures. First of all, the program is supported by many ministries of education, not only monetary, but also by declaring the SWiSE-Schools initiative, or issues linked to it, as one of their priority development programs. Secondly, each school will be supported in the development by a coach who is an expert in science education. Thirdly, all head of schools had to declare that they support the initiative as a whole and their teachers in the implementation. And lastly, the about 130 teachers from 63 schools involved in the initiative get approximately 5\% reduction of their teaching duties during three years (which results in the largest entry in the project budget by far) in order to become involved substantially in the program.

Of course, by putting the teachers in the center and by ensuring the support from the school administrational level, the superior aim of the initiative becomes evident: to show 4- to 16-year-olds possibilities appropriate for their age to access natural sciences and technology and, thereby, to foster their interest and self-confidence in natural sciences and technology.

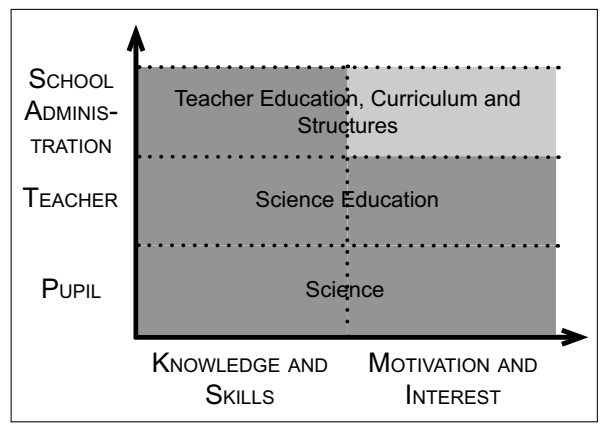

Fig. 5. Schematic classification of the project 'SWiSE-Schools', according to the two-dimensional framework.
Fig. 5 illustrates that in this large project both fields of objectives are addressed on all three levels. In our opinion, this is a prerequisite to obtain a lasting increase in interest and skills in science related topics (pupils) and/or science education (teachers). The initiative started in 2012 and will run till 2015. The outcomes of the initiative will be evaluated by a dedicated research program which started in parallel. First results are expected in 2014.

\section{Discussion}

We would like to note that the grey shading (and therefore the emphasis assigned to the different elements) in Figs 2-5 represents the interpretation of the authors. There are no strict rules on how we assigned the shadings. However, we followed the rule that elements that represent a clear focus of a program or initiative get a dark grey shading, elements which represent side-foci get a light grey shading, while all other elements stay white. Although being a bit simplistic, this leads to a graphical classification of the projects, which represents the key issues of a program (with respect to the dimensions chosen).

We do not state that programs or initiatives having many elements shaded in grey are good programs, while others, having only few elements shaded in grey, are bad programs. This would be far too simple. It is still the content and/or implementation quality of an initiative which is the key parameter for success. However, one has to bear in mind that the scope of a program with a single focus, e.g. on the level of the pupils, will be limited to pupils. On the other hand, a program involving a variety of objectives on several levels can have at least in principle - a wide scope, but is highly demanding in terms of coordination and will most likely cost more money.

Still, we would like to stress a few important points. To our knowledge, there exist quite a few initiatives having a clear (single) focus on pupils. Often, these programs are combined with a feedback form and the results are interpreted as supportive for the success of the program (e.g. the development of interest in science topics). This is a bit dangerous because the development of interest is not perceivable in a single event. Interest and motivation are personal attributes which do not change quickly. They are rather stable and usually only change over months or years. ${ }^{[11]}$ That is why the most sustainable way to influence these personal attributes is still school (besides, of course, the personal and family environment of pupils). This is why we think that initiatives combining the pupil's and teacher's level (and ideally 
including the school administration level) potentially have the greatest impact. When planning such a bridge or link to regular school classes, one has to be aware that most primary school teachers and many secondary one level science teachers have no or only very limited knowledge about science, so they have to be introduced carefully and appropriately (not presuming too much knowledge). This is not the fault of the teachers because traditionally in Switzerland science and science education simply played (almost) no role in teacher education (at primary school level) or because there is a lack of educated science teachers at secondary one level.

The linking of levels, however, is not an easy task. Not only conceptually, especially concerning the funding. A large program such as the SWiSE-Schools project described above, would not be possible without substantial financial support of foundations (in the MCHF range). The industry is more interested in the funding of well-defined projects over short periods of time with a clear focus on pupils and with (seemingly) well defined or traceable impact. However, in our opinion, these initiatives bear the risk of remaining isolated episodes in the school life of a pupil and their impact therefore remains limited.

We hope that our two-dimensional framework and the way we propose to use it for the classification of outreach initiatives in the area of science education in general or, more specifically, in molecular sciences, represents a valuable complementary tool for evaluation or planning.

\section{Acknowledgements}

We would like to thank our collaborators for their contributions to the various projects described. Fritz Gassmann and Franz Theiler (iLab), Nora Zimmermann, Simon Haller, Giorgio Nadig und Michael Weibel (Strawberries in Winter) Monika Hall, Jürg Keller, Christian Rytka, Hans-Jörg Stark and their coworkers (Hi-Tec) as well as the many people involved in the project SWiSE. Furthermore, we acknowledge financial support by BKS Aargau and PSI (iLab), BAFU (Strawberries in Winter), FHNW, PSI and Kabelwerke Brugg AG (HiTec) and Stiftung Mercator, Avina Stiftung, Ernst Göhner Stiftung as well as 14 cantonal ministries of education (SWiSE).

Received: September 14, 2012

[1] In English, the term 'science' is used instead of the more specific German term 'Naturwissenschaften', classically including the subjects physics, chemistry and biology.

[2] P. Labudde, Physik und Didaktik in Schule und Hochschule 2003, 1, 48.

[3] This statement, as many others in this article, represents a Swiss perspective. Nevertheless, the implications and conclusions developed here may be valid beyond Switzerland and its different cantonal educational systems.

[4] J. Osborne, J. Dillon, 'Science Education in Europe: Critical Reflections. A Report to the Nuffield Foundation', King's College, London, 2008.
[5] W. Gräber, P. Nentwig, T. Koballa, R. Evans, 'Scientific Literacy. Der Beitrag der Naturwissenschaften zur Allgemeinen Bildung', Leske + Budrich, Opladen, 2002.

[6] P. Labudde, K. Möller, Zeitschrift für Erziehungswissenschaft, 2012, 15, 11.

[7] G. D. Nelson, Ripon Quarterly, 1999, 34, issue

[8] S. Bernholt, K. Neumann, P. Nentwig, 'Making it tangible - learning outcomes in science education', Waxmann, Münster, New York, München, Berlin, 2012.

[9] R. W. Bybee, in 'Scientific Literacy', Ed. W. Gräber, C. Bolte, IPN, Kiel, 1997.

[10] OECD, 'PISA 2006: Science Competencies for Tomorrow's World. Volume 1: Analysis', OECD, Paris, 2007.

[11] A. Krapp, M. Prenzel, Int. J. Science Education, 2011, 33, 27.

[12] In cognitive psychology and science education, there has been a long discussion about the differences and definitions of interest and motivation. For an overview see ref. [11].

[13] Science education is a term that integrates various aspects: the teaching taking place in the classroom ('Unterricht'), the pedagogics of how to teach science ('Didaktik') and education in a more general sense as expressed in the German term 'Bildung'. We use this term on purpose because our considerations wish to take into account all these aspects.

[14] EDK, 'Grundkompetenzen für die Naturwissenschaften - Nationale Bildungsstandards', Schweizerische Konferenz der kantonalen Erziehungsdirektoren, Bern, 2011.

[15] PSI, iLab, http://ilab.web.psi.ch/, Accessed 17.8.2012.

[16] Expoforum, 'Erdbeeren im Winter - ein Klimamärchen', www.erdbeerenimwinter. ch/ausstellung/informationen/, Accessed 20.8.2012.

[17] SWiSE, Swiss Science Education, www.swise. 